\title{
PALEOGENE COMMUNITY CHANGE AMONG TERRESTRIAL VERTEBRATES OF THE WESTERN HEMISPHERE
}

STUCKY, Richard K., Dept. of Earth Sciences, Denver Museum of Natural History, 2001 Colorado Blvd., Denver, CO 80205, U.S.A.

Paleogene vertebrate communities in North and South America show dramatic changes in taxonomic composition and ecological organization. Worldwide, mammals diversified substantially following dinosaur extinction (Fig. 1). Most families of living vertebrates appear by the end of the Paleogene. In North America, placental omnivores, herbivores and carnivores dominate mammalian communities, but in South America marsupial carnivores and omnivores and placental herbivores dominate them. Immigration from Asia and Europe to North America of taxa from several placental orders (Perissodactyla, Primates, Artiodactyla, Rodentia, Carnivora, Mesonychia, Creodonta) occurred periodically during the Paleogene. South America, however, was completely isolated from the Paleocene to the Oligocene when Rodentia and perhaps Primates first appear. Despite the independent evolutionary histories of these continents, their constituent species show remarkable convergences in morphological adaptations including body size distributions, dental morphology, and other features. Low resolution chronostratigraphic data for the Paleogene of South America precludes correlation with North American faunas. In North America, patterns of diversification and extinction appear to be related to climatic events. Morphological convergences appear to be related to climate and concomitant habitat change, but may also be a function of coevolution via predator-prey interactions and diffuse competition among guild members.

Figure 1. Richness and first and last appearances of mammalian families, worldwide. Note rapid diversification following the $\mathrm{K}-\mathrm{T}$ boundary. Key: $\mathrm{LE}=$ late Eocene; $\mathrm{MO}=$ middle

Oligocene; $\mathrm{MM}=$ middle Miocene; PL=Pleistocene. Data from R. Stucky and M. McKenna (in press). Mammalia. In M. Benton and M. Whyte (eds.), The Fossil Record, 2nd ed.

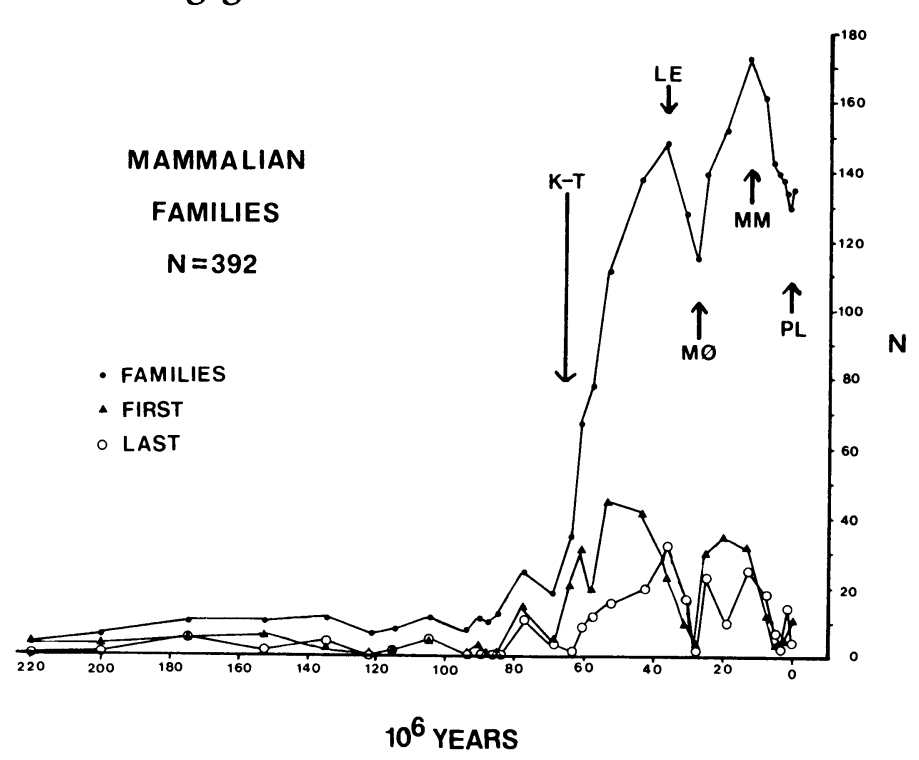

